\title{
Immediate/Early Loading
}

National Cancer Institute

\section{Source}

National Cancer Institute. Immediate/Early Loading. NCI Thesaurus. Code C118645.

The attachment of a prosthetic to an implant prior to the traditional four-six month wait period. 